DOI 10.15593/2224-9354/2018.3.7

УДК 316.662

\title{
P.P. Насибуллин
}

\author{
«МЕСТО ЖИТЕЛЬСТВА» КАК ПОКАЗАТЕЛЬ \\ СОЦИАЛЬНОГО СТАТУСА
}

В предметном поле социологической науки место жительства представляет собой важнейшую точку в системе координат, характеризующий положение человека в социальном пространстве. В статье раскрывается социальное содержание понятия «место жительства», с одной стороны, как одного из многих показателей позиции человека в социальном пространстве города; с другой стороны, как грань социального статуса человека. В процессе формирования новой системы общественных отношений возникают и новые противоречия: если раньше в сфере производства и распределения места жительства основная роль принадлежала государству, а эксплуатация жилья происходила в сущности на основе «государственно-частного партнерства», то сегодня здесь ситуация существенно меняется, оставаясь противоречивой. Раскрываются в статье также возможности применения понятия «место жительства» в социологическом исследовании имущественной характеристики социального статуса молодого жителя города.

Ролевая позиция в определении места молодежи в социальном пространстве города многогранна и имеет свои определенные характеристики: место жительства отражает позицию человека в социальном пространстве с рождения, где он получает первичную социализацию, осваивает элементарные человеческие навыки общения с другими людьми, хотя и по крови родными, но иными, в пространстве, которое отделено от реального мира реальными стенами; здесь индивида скрывает от общества «собственное Я» и т.д.

Как известно, отечественная социологическая наука имеет давние традиции в исследовании социальной структуры городских агломераций. Однако, если прежде в формировании социального пространства города главную роль играло разделение труда, то сегодня место жительство достается молодому поколению по наследству, порождая новые противоречия в социальных отношениях.

Ключевые слова: социальное пространство, место жительства, молодежь, жилищные проблемы, грани социального статуса, имущественная характеристика социального положения.

Актуальность пространственного анализа жизни и жилищных условий различных групп населения обусловлена переходным характером отношений между людьми по вопросу позиции в отношении проживания в социальном пространстве городской агломерации от прежних, которые определялись государственной системой создания, распределения жилья к новым, частнособственническим отношениям. При этом процесс перехода сопровождается конструированием новых противоречий: если раньше в сфере производства и распределения места жительства господствовало государство, а эксплуатация жилья происходила в сущности на основе «государственно-частного партнерства», то сегодня здесь ситуация начинает меняться, оставаясь противоречивой. С одной стороны, государство пытается освобождаться от этих про-

(с) Насибуллин Р.P., 2018

Насибуллин Рустем Равилевич - канд. социол. наук, доцент кафедры социологии и социальных технологий ФГБОУ ВО «Уфимский государственный авиационный технический университет», e-mail: rustem_n@list.ru. 
блем, возникающие структуры самоуправления пытаются организоваться, но с другой стороны, не хватает пока необходимых условий, недостаточно реформирована система институций, не выработано соответствующее мышление хозяйствующих субъектов, господствует прежняя «совковая» социальная психология, не получили развития новые нормы в отношениях между гражданином и государством и т.д. Особенно важно изучение указанных проблем в современном обществе, когда интенсифицируется содержание социальных практик [1, с. 49], происходят социальные катаклизмы, акцентируются процессы, вызванные социальным неравенством, в том числе и отражением на положении молодежи в социальном пространстве города, ее участия в процессах «производства, распределения и потребления» жилья как элемента совокупного общественного богатства и социального статуса.

Необходимо отметить, несмотря на то, что в нашей науке проблема социального пространства занимает особую позицию, приходится соглашаться с мнением, что сам термин «социальное пространство» является скорее дискуссионным концептом, нежели аналитически обоснованным понятием [1, с. 50]. Больше того, время от времени поднимается даже вопрос об авторстве и времени применения самого термина «социальное пространство» [2, с. 64]. При этом основоположником социологии пространства, исследователем называют то немецкого философа и социолога Г. Зиммеля, который ввел в научный оборот этот термин (1903) [3, с. 217], то французского социолога П. Бурдье $[4$, c. 37], использующего это понятие в работе «Физическое и социальное пространства: проникновение и присвоение» (1990) [5, с. 49-64], почему-то не замечая П.Сорокина [6, с. 300], что чем-то напоминает суждения Р. Мертона о предоткрытии в науке [7, с. 33].

Отложив выяснение первенства в использовании понятия «социальное пространство», автор в большей степени хочет определить цель, которая в большей мере соответствует изучению проблемы данной статьи: «социальное пространство - это поле социальной деятельности, включающее совокупность значимых социальных групп, индивидов, объектов в том или ином их взаимном расположении; представление индивида или группы о своем месте в обществе» $[8$, с. 273$]$.

Автор представляет городское социальное пространство как структуру, воплощающую в себя сложные взаимозамещения неких позиций, занятых различными отличающимися друг от друга символическими показателями, явлениями, людьми и отношениями между ними, которые в то же время позволяют определить их положение в социальном пространстве. Каждый элемент, такой как дом или человек, каждое явление или событие имеет в городском пространстве свое определенное место; явление или процесс также индивидуален, в том числе благодаря тому, что они привязаны к определенному месту и реализуются в определенное время в определенной системе координат. 
«Место жительства» - значимый вектор абстрактной позиционной системы, отражающий персональную позицию индивида в социальном пространстве, в том числе пространстве крупного города. Ролевая позиция в жизни человека вообще и в определении места молодежи в социальном пространстве города многогранна.

Одна из граней или характеристик данного вектора отражает ту позицию места жительства в социальном пространстве, где человек проживает с рождения, получает первичную социализацию [9, с. 26], осваивает элементарные человеческие навыки общения с другими людьми, хотя и по крови родными, но иными в пространстве, которое отделено от реального мира стенами. В физическом пространстве, сложенном из этих стен, формируется индивидуальное социальное пространство [10, с. 69], вырабатывается система отношений между своими членами семьи, свой индивидуальный социальный порядок, который поддерживается:

- традициями в семье;

• различными нормами отношений;

- правами и обязанностями членов семьи друг перед другом и в целом к семье;

- отношениями между членами семьи по поводу различного имущества;

- символической системой и т.д.

Кроме этого, здесь определяется роль, место и статус каждого человека $[11$, с. 151$]$ путем применения различных санкций, которые при необходимости могут быть применены, если, например, кто-то будет пытаться нарушить границы определенного ему места. Многие семьи в качестве таких норм ослушавшемуся ребенку определяют угол помещения как место наказания.

Данная традиция весьма интересна - она давно утратила свои корни, но считается весьма эффективной. По старославянским поверьям, с одной стороны, считалось, что в каждой избе, в дальнем темном углу живет «домовой», который отвечал за заботу о доме и его домочадцах. С другой - в избах располагался в углу «красный» уголок с иконами. И в том и в другом случае провинившегося ребенка отправляли в угол на воспитание. По восточным поверьям, угол забирает избыточную энергию, и человек, ощущая утрату энергии, непроизвольно задумывается о содеянном. С научной точки зрения, ребенок осознает виновность, понимая максимальную ограниченность его не только в пространстве физическом, но и в личном или социальном, т.е. общении и ограничении созерцать.

На территории пространства, находящегося на площади «своей» комнаты в доме, ребенок начинает осознавать, что значит «быть своим» и как в то же время можно быть и одиноким, сильным и бессильным в этом общем окружении «своих». 
Другая грань понятия «место жительства» состоит в том, что его территория, ограниченная реальными стенами, скрывает от общества «собственное Я» индивида. С одной стороны, пока индивид не получит первые навыки и правила поведения с другими индивидами, он не попадет в среду «чужих» для семейного окружения. Никто не знает, какой он за стенами, как проходит его социализация, как осваиваются им нормы и в какой степени подготовлен к общению с другими индивидами, находящимися за этими стенами. $\mathrm{C}$ другой стороны, за этими ограниченными пространством стенами протекает социальный процесс развития семейной жизни индивида. Естественно, домашняя и семейная жизнь регулируется в нем правилами и нормами, установленными в обществе в целом. Но, одновременно, в то же самое время каждая отдельная семья по-своему приобщается к этим же нормам и своими индивидуальными методами ретранслирует их на своих детей. В свою очередь, дети физически подрастают, одновременно расширяя свое социальное мировоззрение, поля и границы своего участия в этом пространстве на улице, в школе и т.д. Место жительство в это время у них включает в себя и познание окружающего мира, и игры, и участие в труде взрослых. С возрастом расширяются и рамки социального пространства, которые осваивает человек, уже на выходе из границ места жительства одновременно увеличивается и развивается его круг общения. Но, несмотря на неограниченное расширение этих границ, он все равно остается привязанным к этой точке социального пространства, и даже если этот человек будет находиться в любой другой физической точке своего месторасположения.

Следующая грань смысла «места жительства» отражает конкретную позицию человека в социальном пространстве города в зависимости от социальной иерархии, существующей в этом пространстве, так как место жительство является и имущественным показателем, формой капитала, которая имеет свойство формировать социальное положение человека. Это свойство может проецироваться сегодня на внешний вид домов, их архитектурное оформление и территориальное месторасположение. В отличие от тех времен, когда стремление к социальной однородности породило соответствующие «однородные хрущевки», в которых находили свое место жительство основные массы горожан, и дома, внешне такие же невзрачные, но иначе оформленные внутри, с «местом жительства» вождей разного калибра, сегодня, параллельно с социальным расслоением, мы наблюдаем четко выраженное углубление «архитектурного расслоения» города. В советский период государство худо-бедно, но обеспечивало граждан жильем по месту работы. Качество предоставляемого жилья зависело в основном от положения индивида в иерархической структуре партии и советского государства, трудового стажа, профессионального статуса, размера семьи и пр. Для определенных профессиональных групп строились жилые кварталы: районы для рабочих, номенклатуры, научных сотрудников 
и др. [12, с. 3]. Таким образом, профессиональный и жилищный статусы соотносились друг с другом, а жилищные траектории, как предполагаемые возможности переезда, были вполне предсказуемы [13, с. 50].

Отнесение человека со своим местом жительства как показателем или идентификатором позиции в социальном пространстве сохраняется в социальной памяти поселенческой общности, очень часто специальными мероприятиями и символами, например, прикреплением на стене дома памятной доски с указанием на проживание в этом помещении кого-либо. Кроме того, другие индивиды, по замыслу, должны реагировать на это, в разной степени осознавая свое проживание в этом же доме, где тоже жил указанный на памятной доске человек.

Еще одна грань понятия «места жительства» отражает свою роль в самоидентификации человека как определенного элемента социальной общности, системы, обладая пониманием своей принадлежности к чему-то, что может повлиять на него и формировать в нем интерес и стремление бороться за место в социальном пространстве, т.е. раннее формирование, для дальнейших успехов. То родное, что каждый индивид приобретает в своем родном доме в начале своей жизни, постепенно, в процессе перехода в дальнейшие возрастные группы расширяет, чтобы в конце своей жизни снова вернуть в позицию в пространстве, создаваемом первоначально своим родным домом. Чувство тоски по родному дому и краю, которое не чуждо индивиду, находящемуся за ее пределами, в основе своей есть ни что иное, как чувство тоски по имущественному отражению «родного дома» в рамках, прежде всего своего «места жительства».

Таким образом, понятие «место жительства» как одно из многих показателей позиций человека в социальном пространстве является многогранным, и необходимо понимать, что в каждой из граней могут быть выявлены дополнительные характеристики и структурные элементы.

Самым, пожалуй, популярным (примитивным) и для многих молодых людей первостепенным значением, характеризующим смысл понятия «место жительства», является физическая (имущественная) его характеристика именно то сооружение, состоящее из стен, пола и потолка.

Элементарность формирования данного мнения у людей легко объяснима: человеку, еще даже с «пещерных» времен необходимо убежище, в котором он мог бы согреться, уединиться, приготовить пищу и чувствовать себя в безопасности. А уже в дальнейшем привести в это место другого человека, разделить с ним физическое пространство и осуществлять последующие мероприятия, зарождающие различные социальные процессы, которые позволяют нам судить о многогранности понятия «место жительства».

Жилищная проблема в этом плане всегда являлась и на сегодняшний день является одной из самых насущных, в особенности для молодежи [14]. Поэтому степень остроты жилищных проблем, судя по результатам многочисленных опросов, ощущается в разной степени в возрастных группах молодежи. 
В данном случае интересным представляются результаты исследования по вопросам жилищных проблем, проведенного автором среди молодежи, в возрасте 20-35 лет, в 2016 году в г. Уфа ${ }^{1}$ : большинство респондентов проживает совместно с родителями - 61,1 \%; проживают отдельно - 5,2 \%; на съемной квартире проживают 16,5 \% респондентов от общего числа опрошенных; среди остальных разные ответы, например 8 \% указало, что проживают в общежитии. На одной позиции города 15 \% молодежи, которые проживают в отдельной квартире, на другой - 24 \% не владеющих своим жильем, а в середине - больше половины от общего числа, не владеющих своим жильем и проживающих с родителями.

Естественно, показатели среди молодежи дифференцируются по возрастам: чем старше молодые люди, тем больше среди них тех, которые проживают в отдельной квартире, и чем возрастная группа младше, тем больше проживающих с родителями. Это в общем и понятно. Тот факт, что в группе респондентов до 20 лет проживающие в отдельной квартире составляют $6,7 \%$, может являться фактом наличия у этой части молодежи «своего» места жительства. Но вряд ли можно назвать положительным тот факт, что уже в группе 27-30 лет с родителями проживает почти каждый четвертый опрошенный и не имеет своего жилья столько же.

Жилищные проблемы, по результатам ответов респондентов, имеют разный уровень актуальности среди разного возрастного уровня молодежи. Уже к 18 годам, с одной стороны, с местом жительства имеет проблемы каждый четвертый из респондентов, с другой - проблемы с увеличением возраста обостряются и среди респондентов в возрасте 18-23 года, на что указывает каждый третий респондент (33,0 \%). Среди молодежи 24-30 лет проблемы с «местом жительства» обостряются еще больше, когда у большинства молодых людей уже появляется не только своя семья, но и собственные дети, о чем говорят ответы 41,3 \% опрошенных. В то же время активность молодых людей в решении жилищных вопросов невысока: около 54 \% не имеют понятия, каким образом приобрести для себя жилье и в основном рассчитывают на государство.

Проблема жилищного неравенства чрезвычайно актуальна для молодых и многодетных семей. Исследования показывают, что основа жилищного благополучия многих молодых семей - приватизированное советское жилье, доставшееся по наследству [15, с. 7]. Современное поколение часто не имеет возможности приобретения жилья и, как правило, проживает в наследуемом либо приобретенном родителями. Результаты наших исследований совпадают с результатами и других авторов, что свидетельствует о широкой распространен-

1 Выборочная совокупность анкетного опроса составила 600 чел. в возрасте 20-35 лет. Выборка квотная, пропорциональная половозрастному составу генеральной совокупности и территориальному распределению населения по городским районам. В исследовании приняли участие $56 \%$ женского и $44 \%$ респондентов мужского пола. 
ности явления. В частности автор пишет: «Наиболее депривированы домохозяйства с детьми до 18 лет. Жилищный вопрос актуален для семей многих поколений, когда имеется тенденция проживания взрослых детей с родителями. Лучше в этом ракурсе выглядят граждане в начале и в конце жизненного пути, живущие либо одиноко, либо с супругом» [16, с. 282].

Жилищные проблемы молодежи и всего населения всегда останутся актуальными. В связи с этим хотелось бы обратить внимание и на позицию П. Бурдье: «Структура социального пространства определяется в каждый момент структурой распределения капитала и прибыли, специфического для каждого отдельного поля» $[17$, с. 31$]$. Географическое и социальное пространства никогда не совпадают полностью, однако, по мнению ученого, эффекты, свойственные первому, например выделение периферии и центра, можно действительно назвать дистанцией в социальном пространстве, так как это связано с различием в распределении различных видов капитала. Помимо этого, Бурдье размышляет о пространстве и как о статусной структуре, подчеркивая, что любое общество имеет свою непременную иерархию, что приводит к отражению в пространстве физическом: «Социальное пространство - не физическое пространство, но оно стремится реализоваться в нем более или менее полно и точно» [6, с. 53].

Результаты исследования дают основание считать, что существующие в настоящее время социальные отношения характеризуются особенностями перехода от одного качественного состояния к другому - перехода от бесплатного государственного распределения жилья к рыночным условиям, порождающим противоречия и рассогласованность между социальным статусом и жилищной обеспеченностью населения. Примером может являться группа пенсионеров, проживающих в престижных городских районах, владеющих дорогостоящим жильем, но мало обеспеченных ресурсами в других сферах (денежные доходы, здоровье, профессиональные позиции).

\section{Список литературы}

1. Барковская А.Ю. Социологическая интерпретация категории «Социальное пространство» // Вестник Волгогр. ун-та. Сер. 7. Философия. - 2013. №(19). - С. 49-55.

2. Филиппов А.Ф. Социология пространства. - СПб.: Владимир Даль, 2008. -290 c.

3. Зиммель Г. Социология пространства // Избранное: в 2 т. - Т. 2. Созерцание жизни. - М.: Юристь, 1996. - 607 с. - (Серия «Лики культуры»).

4. Терещенко М.С. Социальное пространство // Социология: энцикл. / сост.: А.А. Грицанов [и др.]. - Минск: Кн. дом, 2003. - С. 37.

5. Бурдье П. Физическое и социальное пространства: проникновение и присвоение // Социология социального пространства / Ин-т эксперим. социологии. - СПб.: Алетейя, 2005. - С. 49-63. 
6. Сорокин П. Социальная и культурная мобильность // Сорокин П. Человек. Цивилизация. Общество. - М., 1992.- С. 297-424.

7. Мертон Р. Социальная теория и социальная структура. - М.: АСТ: Хранитель, 2006. - 873 с.

8. Социологический энциклопедический словарь / под ред. Г.В. Осипова. M.: HOPMA, 2000. $-273 \mathrm{c}$.

9. Окольская Л.А. Социализация с точки зрения социального конструктивизма и теорий социального воспроизводства // Вопросы воспитания. 2010. - № 1 (2). - C. 25-33.

10. Падерин В.К., Митрошина О.В., Гатин И.Д. Индивидальное пространство как объект социологического анализа: к постановке проблемы // Казанский социально-гуманитарный вестник. - 2017. - № 5(28). - С. 69-73.

11. Социология: учеб. / В.И. Добреньков, В.Н. Нечипуренко, А.В. Попов; под ред. проф. Ю.Г. Волкова. - Изд. 2-е, испр. и доп. - М.: Гардарики, 2004. $-512 \mathrm{c.}$

12. Меерович М.Г., Конышева Е.В., Хмельницкий Д.С. Кладбище соцгородов: градостроительная политика в СССР (1928-1932 гг.). - М.: РОССПЭН, 2011. $-270 \mathrm{c}$.

13. Полухина Е.В., Горяйнова А.Р. Жилищные траектории московских семей в XX веке как объект вторичного анализа биографических интервью // ИНТЕРакция. ИНТЕРвью. ИНТЕРпретация. - 2015. - № 10. - С. 47-59.

14. Молодежь Свердловской области на рубеже веков: проблемы, тенденции, ориентиры. - Екатеринбург, 2002. - С. 75-76.

15. Zavisca J.R. Housing the New Russia. - Ithaca, NY: Cornell University Press, 2012. $-257 \mathrm{p}$.

16. Бурдяк А.Я. Обеспеченность жильем в постсоветской России: неравенство и проблема поколений // Журнал исследований социальной политики. - 2015. - № 13 (2). - С. 273-288.

17. Бурдье П. Социальное пространство и генезис классов // Социология социального пространства / Ин-т эксперим. социологии. - СПб: Алетейя, 2007. - С. 14-49.

\section{References}

1. Barkovskaia A.Iu. Sotsiologicheskaia interpretatsiia kategorii "Sotsial'noe prostranstvo" [Sociological interpretation of the category of "social space']. Science Journal of Volgograd State University. Philosophy. Series 7, 2013, no. 19, p. 49.

2. Filippov A.F. Sotsiologiia prostranstva [The sociology of space]. Saint Petersburg, Vladimir Dal', 2008, p. 64.

3. Zimmel' G. Sotsiologiia prostranstva [The sociology of space]. Sozertsanie zhizni, vol. 2, Moscow, 1996, Jurist, p. 217. 
4. Tereshchenko M.S. Sotsial'noe prostranstvo [The social space]. Sotsiologiia. Encyclopedia. Minsk, Knizhnyi dom, 2003, p. 37.

5. Burd'e P. Fizicheskoe i sotsial'noe prostranstva: proniknovenie i prisvoenie [Physical and social spaces: penetration and appropriation]. Ed. N.A. Shmatko. Saint Petersburg, Aleteiia, 2005, pp. 49-64.

6. Sorokin P. Sotsial'naia i kul'turnaia mobil'nost' [Social and cultural mobility]. Chelovek. Tsivilizatsiia. Obshchestvo. Moscow, 1992, p. 297-424.

7. Merton R. Sotsial'naia teoriia i sotsial'naia struktura [Social theory and social structure]. Moscow, AST Moskva, Khranitel', 2006, p. 33.

8. Sotsiologicheskii entsiklopedicheskii slovar' [Encyclopedia of sociology]. Ed. G.V. Osipov. Moscow, NORMA, 2000, 273 p.

9. Okol'skaia L.A. Sotsializatsiia s tochki zreniia sotsial'nogo konstruktivizma i teorii sotsial'nogo vosproizvodstva [Socialization from the point of view of social constructivism and theories of social reproduction]. Voprosy vospitaniia, 2010, no. 1(2), p. 26.

10. Paderin V.K., Mitroshina O.V., Gatin I.D. Individal'noe prostranstvo kak ob"ekt sotsiologicheskogo analiza: k postanovke problemy [Individual space as an object of sociological analysis: problem statement]. Kazan Socio-Humanitarian Bulletin, 2017, no. 5, p. 69-73.

11. Dobren'kov V.I., Nechipurenko V.N., Popov A.V. Sotsiologiia [Sociology]. Moscow, Gardariki, 2004, 512 p.

13. Polukhina E.V., Goriainova A.R. Zhilishchnye traektorii moskovskikh semei v XX veke kak ob"ekt vtorichnogo analiza biograficheskikh interv'iu [Housing trajectories of Moscow families in the XX century as the object of secondary analysis of biographical interviews]. INTERaktsiia. INTERv'iu. INTERpretatsiia, 2015, no. 10, pp. 47-59.

14. Molodezh' Sverdlovskoi oblasti na rubezhe vekov: problemy, tendentsii, orientiry [Young people of the Sverdlov region at the turn of the centuries: problems, trends, key points]. Ekaterinburg, 2002, pp. 75-76.

15. Zavisca J.R. Housing the new Russia. Ithaca, New York, 2012, Cornell University Press, p. 7.

16. Burdiak A.Ia. Obespechennost' zhil'em v postsovetskoi Rossii: neravenstvo i problema pokolenii [Housing in post-Soviet Russia: inequality and the problem of generation]. The Journal of Social Policy Studies, 2015, no. 13(2), pp. 273-288.

17. Burd'e P. Sotsial'noe prostranstvo i genezis klassov [Social space and the genesis of classes]. Saint Petersburg, Aleteiia, 2007, pp. 14-49.

Оригинальность $78 \%$

Получено 28.12.2017 Принято 29.01.2018 Опубликовано 28.09.2018 


\section{R.R. Nasibullin \\ "RESIDENCE” AS AN INDICATOR OF SOCIAL STATUS}

In the subject field of sociological science, the place of residence is the most important point in the coordinate system characterizing the position of a person in social space. The article reveals the social content of residence concept, on the one hand, as one of many indicators of a person's position in the social space of the city; on the other hand, as a borderline of a person's social status. In the process of forming a new system of social relations new contradictions also arise: if earlier the main role in the sphere of production and distribution of residence place was played by the state, and the exploitation of housing took place in essence on the basis of "public-private partnership", today the situation is substantially changing, remaining contradictory. The article also reveals the possibilities of applying the "place of residence" concept in sociological study of the property characteristic of the social status of a young citizen.

The role position in definition of the place of youth in social space of the city is multifaceted and has its own specific characteristics: the residence reflects the position of a person in the social space from birth, where he or she receives primary socialization, mastering the elementary human skills of communication with other people, though blood relatives, but different, in space which is separated from the real world by real walls; here "I myself" hides the individual from society, etc.

As it is known, Russian sociological science has a long tradition of studying the social structure of urban agglomerations. However, if before the formation of the social space of the city the main role was played by the division of labor, today the place of residence is inherited by younger generation, creating new contradictions in social relations.

Keywords: social space, place of residence, youth, residence challenges, borderlines of social status, material characteristics of social status.

Rustem R. Nasibullin - Candidate of Sociological Sciences, Associate Professor, Department of Sociology and Social Technologies, Ufa State Aviation Technical University, e-mail: rustem_n@list.ru.

Received 28.12.2017 Accepted 29.01.2018 Published 28.09.2018 